\title{
Different LNA Topologies Designed with HEMT Technologies at Ka and Q Bands
}

\author{
Lakshmi Balla, Venkata Krishna Sharma Gollakota, Sandhya Teku
}

\begin{abstract}
The main drawback of designing LNA with CMOS technology is the high power dissipation. This problem can be overcome by designing LNA with HEMT technology. In this paper we went through several LNA's designed with different HEMT technologies from the past few decades. Assessment of different LNA topologies with HEMT technologies around ka and $Q$ band is performed in this paper along with EM simulations of PP1010 unconditionally stable LNA.
\end{abstract}

Keywords: Complementary metal oxide semiconductor (CMOS); Low noise amplifier (LNA); Radio Frequency $(R F)$; High electron mobility transistor (HEMT);

\section{INTRODUCTION}

$\mathrm{T}$ LNA is key building block of RF receiver of wireless communication. LNA amplifies the received weak signal from an antenna at low noise level. As LNA is starting building block of the entire receiver system, LNA should be designed with low noise figure (NF) to maintain overall receiver NF low. LNA is used in numerous applications like radio astronomy applications, wireless local area networks, telecommunications, radar systems and satellite communications etc. Basic features of LNA are NF, gain, input and output return losses (IRL, ORL). All these features are represented by S parameters of the amplifier. Along with these features linearity, dynamic range, bandwidth, stability and power dissipation are also the important features to be considered while designing a LNA.

From the overall research, LNA design topologies with HEMT technologies are briefly classified into 6 sections. 1) The basic common source (CS) topology [1, 2] offers low NF but moderate gain compared to the other topologies. 2) CS topology with source degenerated with inductor $[3,4]$ offers good trade-off between NF and gain. 3) Self bias topology [5, 6] avoids applying the bias at the gate of the HEMT. 4) Current reuse topology [7] where the same current flows through the two HEMT's with both gates of the HEMTs grounded. 5) Distributed topology [8] where all the gates are connected to same point and all drains are connected to same point such that it leads to ultra wide bandwidth. 6) Resistive feedback topology [9] where the resistor is used in between the gate and drain such that it compensates the effect of cgd

Revised Manuscript Received on December 13, 2019.

* Correspondence Author

Lakshmi Balla*, EECE, Gitam deemed to be University, Visakhapatnam, India. Email: ballalakshmi79@gmail.com

Venkata Krishna Sharma Gollakota, EECE, Gitam deemed to be University, Visakhapatnam, India. Email: gvks007@gmail.com

Sandhya Teku, ECE, Vignan's Institute of Engineering for women, Visakhapatnam, India. Email: teku.sandhya@gmail.com and offers better NF and gain compared to other topologies but offers high NF at low frequency band.

This paper is organized in IV sections. Classification of different topologies for designing LNA using HEMT technology is given in section II. Various LNA's designed in every topology are analysed in section III. Progress of increasing gain and reducing NF of different LNA's are observed in this section. Unconditional stability of PP1010 HEMT LNA and its simulation results are explored in section IV. Conclusion is summarized in section V.

\section{CLASSIFICATION OF HEMT TOPOLOGIES}

Various HEMT topologies of designing a LNA are briefly classified as

1) CS topology

2) CS with source degenerated with inductor topology

3) Self-bias CS/inductive degeneration topology

4) Current reuse common gate topology

5) Distributed LNA topology

6) Resistive feedback topology

\section{COMPARISON OF DIFFERENT TOPOLOGIES OF LNA}

\section{1) CS HEMT topology}

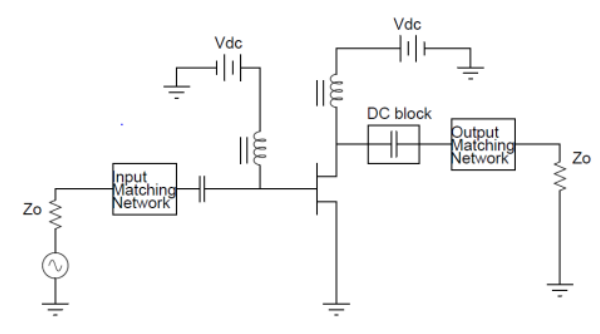

Fig. 1. CS HEMT topology

Basic CS topology of HEMT LNA is shown in Fig. 1, where $\mathrm{dc}$ bias is given to the gate and drain along with the matching networks at input and output side and zo indicates the terminating impedance both at input and output side.

Various CS LNA's with different technologies designed around $\mathrm{Ka}$, Q bands are reported in Table-I. Low NF of 1.8 $\mathrm{dB}$ achieved with $0.07 \mu \mathrm{m}$ GaAs mHEMT [2] and $0.1 \mu \mathrm{m}$ Inp HEMT [1] with CS topology. Finally within CS topology $0.07 \mu \mathrm{m}$ GaAs mHEMT and $0.1 \mu \mathrm{m}$ Inp HEMT offers best NF at Q band. 


\section{Different LNA Topologies Designed with HEMT Technologies at Ka and Q Bands}

Table-I: Comparison table of CS topologies

\begin{tabular}{|c|c|c|c|c|c|c|}
\hline Reference & Technology & Topology & $\begin{array}{c}\text { No.of } \\
\text { stages }\end{array}$ & $\begin{array}{c}\text { Gain } \\
(\mathrm{dB})\end{array}$ & $\begin{array}{c}\text { NF } \\
(\mathrm{dB})\end{array}$ & $\begin{array}{c}\text { Frequency } \\
(\mathrm{GHz})\end{array}$ \\
\hline$[1]$ & $\begin{array}{c}0.1 \mu \mathrm{m} \text { Inp } \\
\text { HEMT }\end{array}$ & CS & 2 & 20 & 1.8 & 44 \\
\hline$[2]$ & $\begin{array}{c}0.07 \mu \mathrm{m} \\
\text { GaAs } \\
\mathrm{mHEMT}\end{array}$ & $\mathrm{CS}$ & 4 & 28.2 & 1.8 & $33-50$ \\
\hline$[1]$ & $\begin{array}{c}0.1 \mu \mathrm{m} \\
\text { GaAs } \\
\text { mHEMT }\end{array}$ & CS & 4 & 28 & 2.5 & 44 \\
\hline
\end{tabular}

2) CS with source degenerated with inductor topology:

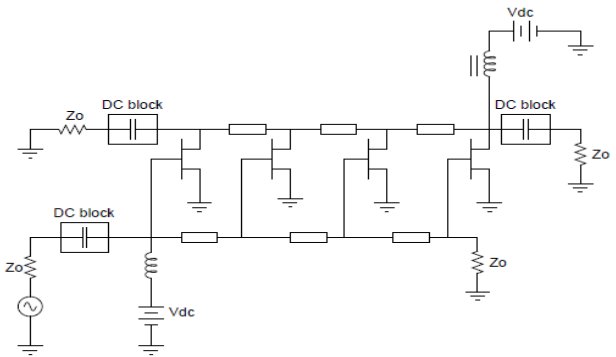

Fig. 2. CS with source degenerated with inductor topology

CS topology with source degenerated with inductor is shown in Fig. 2. It is the extension of CS topology where the source is degenerated with inductor. Generally, transmission line is used as an inductor. Remaining biasing networks, matching networks and terminating impedances are same as with CS topology.

Table- II: comparison table of $\mathrm{CS}$ with inductive degeneration topologies

\begin{tabular}{|c|c|c|c|c|c|c|}
\hline Reference & Technology & Topology & $\begin{array}{c}\text { No.of } \\
\text { stages }\end{array}$ & $\begin{array}{c}\text { Gain } \\
(\mathrm{dB})\end{array}$ & $\begin{array}{c}\text { NF } \\
(\mathrm{dB})\end{array}$ & $\begin{array}{c}\text { Frequency } \\
(\mathrm{GHz})\end{array}$ \\
\hline$[3]$ & $\begin{array}{c}0.15 \mu \mathrm{m} \\
\text { GaAs } \\
\mathrm{pHEMT}\end{array}$ & $\begin{array}{c}\text { c.s with } \\
\text { inductive } \\
\text { degeneration }\end{array}$ & 3 & 22.8 & 1.6 & 28 \\
\hline$[4]$ & $\begin{array}{c}0.15 \mu \mathrm{m} \\
\text { InGaAs } \\
\mathrm{mHEMT}\end{array}$ & $\begin{array}{c}\text { c.s with } \\
\text { inductive } \\
\text { degeneration }\end{array}$ & 3 & 31 & 2.8 & 44 \\
\hline$[4]$ & $\begin{array}{c}0.15 \mu \mathrm{m} \\
\text { InGaAs } \\
\text { mHEMT }\end{array}$ & $\begin{array}{c}\text { c.s with } \\
\text { inductive } \\
\text { degeneration }\end{array}$ & 3 & 28 & 2.6 & 44 \\
\hline
\end{tabular}

Various CS with inductive degenerated LNA's designed at different HEMT technologies around $\mathrm{Ka}, \mathrm{Q}$ band are reported in Table- II. Using inductive degeneration $0.15 \mu \mathrm{m}$ GaAs pHEMT [3] results a low NF of 1.6 at Ka band. High gain of $31 \mathrm{~dB}$ achieved with $0.15 \mu \mathrm{m}$ InGaAs mHEMT [4].

3) Self bias CS inductive degeneration topology:

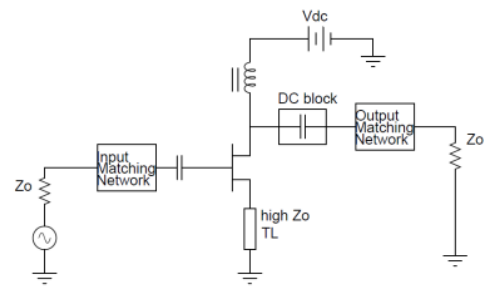

Fig. 3. Self bias CS with source degenerated with inductor topology
Self bias CS topology with source degenerated with inductor is shown in Fig 3. In previous topology gate is biased with the dc supply, whereas self bias topology avoids the bias at the gate of the HEMT, and transmission line is used as inductive degeneration. Biasing networks, matching networks, terminating impedances are similar with other topologies.

Table- III: comparison table of self bias CS inductive degeneration topology

\begin{tabular}{|c|c|c|c|c|c|c|}
\hline Reference & Technology & Topology & $\begin{array}{c}\text { No.of } \\
\text { stages }\end{array}$ & $\begin{array}{c}\text { Gain } \\
(\mathrm{dB})\end{array}$ & $\begin{array}{c}\mathrm{NF} \\
(\mathrm{dB})\end{array}$ & $\begin{array}{c}\text { Frequency } \\
(\mathrm{GHz})\end{array}$ \\
\hline$[5]$ & $\begin{array}{c}0.15 \mu \mathrm{m} \mathrm{GaAs} \\
\mathrm{pHEMT}\end{array}$ & $\begin{array}{c}\text { Self bias c.s } \\
\text { with } \\
\text { inductive } \\
\text { degeneration }\end{array}$ & 2 & 18 & 1.5 & $42-44$ \\
\hline$[5]$ & $\begin{array}{c}0.15 \mu \mathrm{m} \text { GaAs } \\
\mathrm{pHEMT}\end{array}$ & $\begin{array}{c}\text { Self bias c.s } \\
\text { with } \\
\text { inductive } \\
\text { degeneration }\end{array}$ & 2 & 19 & 1.55 & $42-44$ \\
\hline$[6]$ & $\begin{array}{c}0.07 \mu \mathrm{m} \\
\mathrm{AlGaAs/InGaAs} \\
\mathrm{mHEMT}\end{array}$ & $\begin{array}{c}\text { Self bias c.s } \\
\text { with } \\
\text { inductive } \\
\text { degeneration }\end{array}$ & 3 & 20 & 2.5 & 40 \\
\hline
\end{tabular}

Different LNA's with CS self bias inductive degeneration around Q band are reported in Table III. Low NF of $1.5 \mathrm{~dB}$ obtained with $0.15 \mu \mathrm{m}$ GaAs pHEMT [5]. High gain of $20 \mathrm{~dB}$ obtained with $0.07 \mu \mathrm{m} \mathrm{AlGaAs/InGaAs} \mathrm{mHEMT} \mathrm{[6].}$

\section{4) Current reuse common gate (CCG) topology}

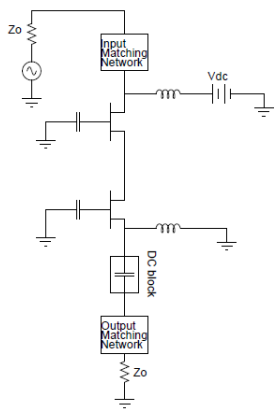

Fig. 4. current reuse common gate topology

CCG topology is shown in Fig. 4. In contrast to other topologies gates of both HEMT's are grounded in this topology and same current is passed through the both the HEMT's.

Table-IV: comparison table of current reuse common gate topology

\begin{tabular}{|c|c|c|c|c|c|c|}
\hline Reference & Technology & Topology & $\begin{array}{c}\text { No.of } \\
\text { stages }\end{array}$ & $\begin{array}{c}\text { Gain } \\
(\mathrm{dB})\end{array}$ & $\begin{array}{c}\text { NF } \\
(\mathrm{dB})\end{array}$ & $\begin{array}{c}\text { Frequency } \\
(\mathrm{GHz})\end{array}$ \\
\hline$[7]$ & $\begin{array}{c}0.12 \mu \mathrm{m} \\
\mathrm{GaN} \\
\mathrm{pHEMT}\end{array}$ & CCG & 2 & 15 & 3 & $33-41$ \\
& & & & & \\
\hline
\end{tabular}

Up to authors knowledge very few works found with current reuse common gate topology. The major drawback of the common gate topology is it offers relatively

high NF compared to CS topology. Low input impedance offered by 

LNA. This $0.12 \mu \mathrm{m}$ GaN pHEMT LNA [7] obtained a degraded performance in terms of NF and gain relative to GaAs HEMT LNA.

5) Distributed LNA topology:

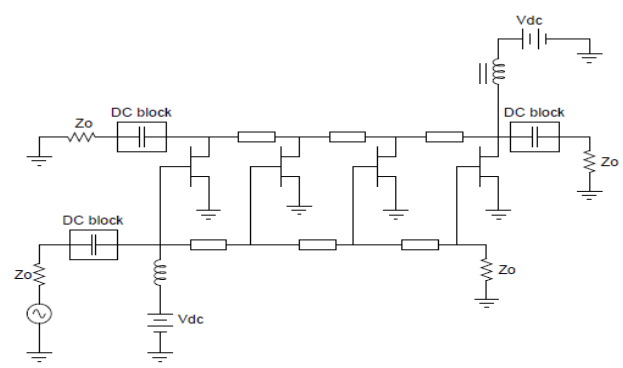

Fig. 5: Distributed LNA topology

Distributed LNA topology using HEMT technology is as shown in Fig. 5. In contrast to the other topologies all the gates are connected to one point and all the drains are connected to one point and applied with bias, whereas all sources are grounded. This topology results an ultra wide bandwidth.

Table-V: comparison table of Distributed Low noise amplifier topology

\begin{tabular}{|c|c|c|c|c|c|c|}
\hline Reference & Technology & Topology & $\begin{array}{c}\text { No.of } \\
\text { stages }\end{array}$ & $\begin{array}{c}\text { Gain } \\
(\mathrm{dB})\end{array}$ & $\begin{array}{c}\text { NF } \\
(\mathrm{dB})\end{array}$ & $\begin{array}{c}\text { Frequency } \\
(\mathrm{GHz})\end{array}$ \\
\hline$[8]$ & $\begin{array}{c}0.15 \mu \mathrm{m} \\
\mathrm{GaAs} \\
\mathrm{pHEMT}\end{array}$ & Distributed & 2 & 15 & 3.3 & $50-60$ \\
& & & & & \\
\hline
\end{tabular}

$0.15 \mu \mathrm{m}$ GaAs pHEMT LNA [8] using distributed method offers degraded performance of high NF and low gain compared with other methods of $0.15 \mu \mathrm{m}$ GaAs pHEMT LNA's [3],[5].

6) Resistive feedback (RFB) topology:

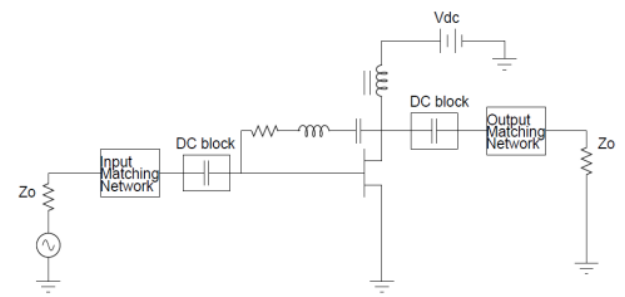

Fig. 6: Resistive feedback topology

Fig. 6. shows the RFB topology. In this topology resistor is connected in between gate and drain of the HEMT to compensate the effect of $c_{g d}$. This topology is competitive with the other topologies in terms of NF and gain but its performance is degrades at lower frequencies.

Table- VI: comparison table of resistive feedback amplifier

\begin{tabular}{|c|c|c|c|c|c|c|}
\hline Reference & Technology & Topology & $\begin{array}{c}\text { No.of } \\
\text { stages }\end{array}$ & $\begin{array}{c}\text { Gain } \\
(\mathrm{dB})\end{array}$ & $\begin{array}{c}\text { NF } \\
(\mathrm{dB})\end{array}$ & $\begin{array}{c}\text { Frequency } \\
(\mathrm{GHz})\end{array}$ \\
\hline$[9]$ & $\begin{array}{c}0.15 \mu \mathrm{m} \text { E- } \\
\text { mode GaAs }\end{array}$ & $\begin{array}{c}\text { Resistive } \\
\text { feedback }\end{array}$ & 4 & 30 & 1.25 & $14-31$ \\
\hline
\end{tabular}

common gate topology is the important feature in designing

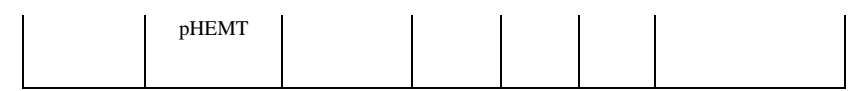

From Table- VI it can be observed that $0.15 \mu \mathrm{m}$ E- mode GaAs pHEMT [9] resistive feedback topology gives a very low NF of $1.25 \mathrm{~dB}$ relative to the remaining all topologies. However resistive feedback causes high NF at low frequency band like $\mathrm{L}$ band.

\section{SIMULATION RESULTS OF PP1010 HEMT LNA}

PP1010 HEMT is selected as active device for designing LNA. The characteristics of Ids vs Vds over fixed Vgs and Ids vs Vgs over fixed Vds of the PP1010 HEMT are shown in Fig. 7 and Fig. 8 respectively.

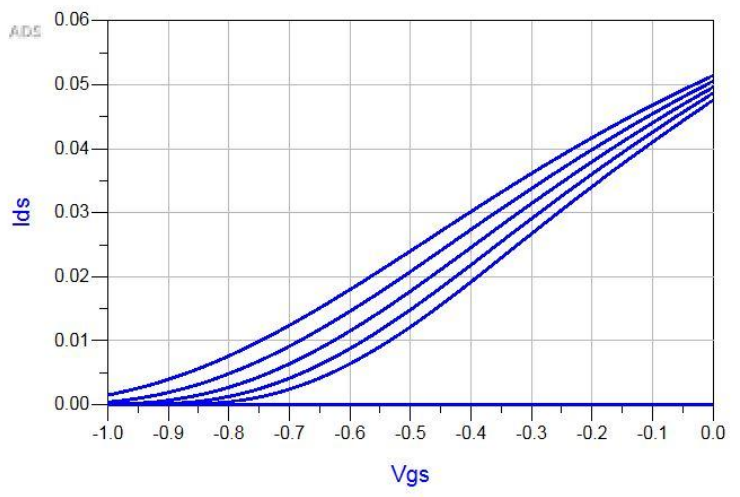

Fig. 7: Ids vs Vgs curve of PP1010 for fixed Vds

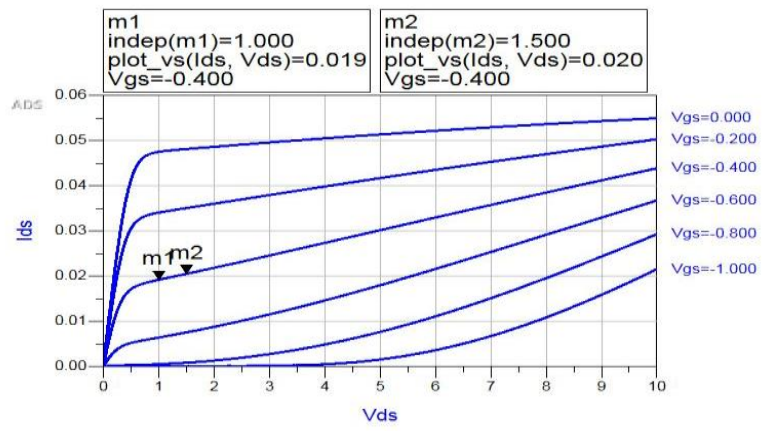

Fig. 8: Ids vs Vds curve of PP1010 for fixed Vgs It can be observed from the Fig. 7 and Fig. 8 that the cutoff voltage for PP1010 HEMT is around $-0.725 \mathrm{~V}$ at $\mathrm{Vds}=1.5 \mathrm{~V}$. Hence Vgs of PP1010 HEMT is to be maintained above $-0.725 \mathrm{~V}$.

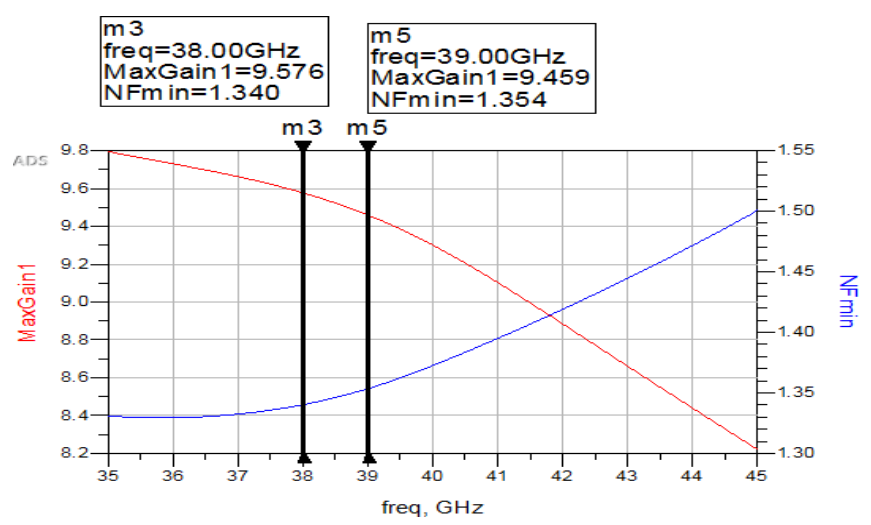

Fig. 9: MaxGain, NFmin vs Frequency 


\section{Different LNA Topologies Designed with HEMT Technologies at Ka and Q Bands}

For low noise figure, PP1010 HEMT has to be biased at $10-15 \%$ of Idss.

When PP1010 HEMT is biased for Vgs of $-0.4 \mathrm{~V}$ and Vds swept from $0-2 \mathrm{~V}$, NFmin of $1.34 \mathrm{~dB}$ and maximum gain of $9.576 \mathrm{~dB}$ is obtained as shown in Fig. 9. Reducing the bias current gives a smaller NFmin, but the gain decreases as well. The bias current of $19 \mathrm{~mA}$ is a trade-off between NFmin and maximum gain.

\section{CONCLUSION}

Analysis of different LNA topologies with HEMT technologies from the past decades has been performed. Comparison is mainly concentrated on NF and gain parameters. Out of all topologies resistive feedback topology with $0.15 \mu \mathrm{m}$ E- mode GaAs pHEMT offers better performance at $\mathrm{K}_{\mathrm{a}}$ band but performance is degraded at $\mathrm{L}$ band and $0.15 \mu \mathrm{m}$ GaAs pHEMT with $\mathrm{CS}$ and source degenerated with inductor topology results a better performance at Q band. EM simulations of PP1010 HEMT LNA are performed. Results exhibit the accuracy of developed EM model.

\section{REFERENCES}

1. M. V, Aust., T. W , Huang., M, Dufault., H,Wang,., , D. C. W,LO; Lai, R.,\& C. C ,Yang. (1996, June). Ultra low noise Q-band monolithic amplifiers using InP-and GaAs-based $0.1 / \mathrm{spl} \mathrm{mu} / \mathrm{m}$ HEMT technologies. In IEEE 1996 Microwave and Millimeter-Wave Monolithic Circuits Symposium. Digest of Papers (pp. 89-92). IEEE.

2. B,Aja., L, de la Fuente., E, Artal., \& Collantes, J. V. T. (2016, October). Cryogenic broadband Q-band MMIC low-noise amplifier. In 2016 11th European Microwave Integrated Circuits Conference (EuMIC) (pp. 77-80). IEEE.

3. H, Uchida., K, Nakahara., S, Takatsu., Katoh, T., Itoh, Y., Imai, R., \& Kadowaki, N. (1999). Ka-band multistage MMIC low-noise amplifier using source inductors with different values for each stage. IEEE microwave and guided wave letters, 9(2), 71-72.

4. H. P, Moyer., T,Lee., M, Micovic., R. O, Hiramoto., A, Kurdoghlian., Zaire, M. B., \& Willadsen, P. J. (2008, October). Q-Band GaN MMIC LNA using a $0.15 \mu \mathrm{m}$ T-Gate process. In 2008 IEEE Compound Semiconductor Integrated Circuits Symposium (pp. 1-4). IEEE.

5. M, Vittori., S, Colangeli., G, Polli., E, Limiti., G, Polli., A, Salvucci., $\& \mathrm{~W}$, Ciccognani. (2017, November). Q-band self-biased MMIC LNAs using a $70 \mathrm{~nm}$ InGaAs/AlGaAs process. In 2017 IEEE Asia Pacific Microwave Conference (APMC) (pp. 630-633). IEEE.

6. Wang, Q., \& Guo, Y. (2011, May). Ka-band self-biased monolithic gaas pHEMT low noise amplifier. In 2011 IEEE International Conference on Microwave Technology \& Computational Electromagnetics (pp. 261-263). IEEE.

7. Y, Kamada., M, Sat., Y, Niida., S, Ozaki., K, Joshin., K, Makiyama., \& T, Ohki. (2016, May). Q-Band InAlGaN/GaN LNA using current reuse topology. In 2016 IEEE MTT-S International Microwave Symposium (IMS) (pp. 1-4). IEEE.

8. K, Araki.,T,Nakagawa., K, Kamogawa., K,Nishikawa., \& B,Piernas., (2002, June). Compact LNA and VCO 3-D MMICs using commercial GaAs PHEMT technology for V-band single-chip TRX MMIC. In 2002 IEEE MTT-S International Microwave Symposium Digest (Cat. No. 02CH37278) (Vol. 3, pp. 1717-1720). IEEE.

9. T,Pham., A. V ,Pham., B. L ,Pham., D. P Nguyen., \& B. L Pham,. (2017, June). A 14-31 GHz 1.25 dB NF enhancement mode GaAs pHEMT low noise amplifier. In 2017 IEEE MTT-S

\section{AUTHORS PROFILE}

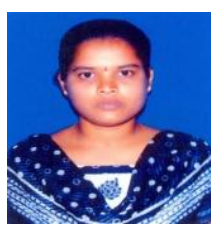

Lakshmi Balla received her B.Tech. in Electronics and Communication engineering from Vignan's institute of information technology, AP, India in 2011 and M.Tech. in Digital Systems and Signal Processing from GITAM University during 2011 - 2013. She had a teaching experience of two years in vignan institute of engineering for women during 2013 - 2015. She is currently pursuing Ph.D in GITAM university. Her research interests include LNA design, PA design at RF.

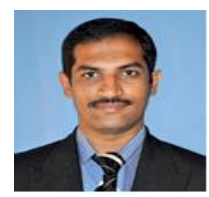

G.V.K. Sharma obtained his Ph.D. and Master's degree from Andhra University and Indian Institute of Science, Bangalore, India respectively. Presently, he is a Professor in the Dept. of ECE, GITAM University, Visakhapatnam, India. His research interests include radar signal processing, RF Integrated Circuit Design and VLSI signal processing.

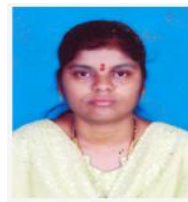

Sandhya Teku received her B.E. from S.R.K.R Engineering college, Bhimavaram and M.Tech from JNT University, Kakinada. Presently pursuing her Ph.D degree from JNT University, Kakinada. Curently working as Associate Professor in the department of ECE, Vignan's Institute of Engineering for women, Visakhapatnam. Her areas of interest include multi-modal image fusion, image enhancement and restoration. She has publications in SCI and scopus indexed journals. 